\title{
ANALISIS KADAR NIKOTIN ROKOK HERBAL INDONESIA
}

\author{
Rahmat Nur Hidayat, Adam M. Ramadhan, Rolan Rusli
}

\begin{abstract}
The phenomenon in society today is believing that herbal cigarettes do not have nicotine. To obtain the appropriate information on the content of nicotine in herbal cigarettes, research identification of secondary metabolites, and analysis of nicotine levels in herbal cigarettes conducted using UV-Vis spectrophotometer at a wavelength of $262 \mathrm{~nm}$. The results showed that the content of secondary metabolites in 5 types of herbal cigarettes studied among other alkaloids, phenols, and terpenoids, whereas saponin obtained only on one single type of herbal cigarettes. The nicotine content of herbal cigarettes per each samples A, B, C, D, and E are at $1.127 \mathrm{mg}, 0.592 \mathrm{mg}, \mathrm{C}: 1.538 \mathrm{mg}, 0.706 \mathrm{mg}$, and 1,213 $\mathrm{mg}$. This indicates that samples $\mathrm{B}$ and $\mathrm{D}$ of herbal cigarettes contain nicotine which is almost the same as the one of a conventional cigarette, while the herbal cigarettes $\mathrm{A}, \mathrm{C}$, and $\mathrm{E}$ have a nicotine content greater than the conventional cigarette.
\end{abstract}

Key word: herbal cigarette, conventional cigarette, content of nikotin

\begin{abstract}
ABSTRAK
Fenomena di masyarakat saat ini adalah meyakini bahwa rokok herbal tidak memiliki kandungan nikotin. Untuk memperoleh informasi yang tepat mengenai kandungan nikotin pada rokok herbal, dilakukan penelitian identifikasi senyawa metabolit sekunder dan analisis kadar nikotin pada rokok herbal dilakukan dengan metode spektrofotometer UVVis pada panjang gelombang $262 \mathrm{~nm}$. Hasil penelitian menunjukkan bahwa kandungan metabolit sekunder pada 5 jenis rokok herbal yang diteliti antara lain alkaloid, fenol, dan terpenoid, sedangkan saponin hanya diperoleh pada satu jenis rokok herbal. Kandungan nikotin perbatang rokok herbal A, B, C, D, dan E adalah berturut-berturut sebesar 1,127 $\mathrm{mg}, 0,592 \mathrm{mg}, 1,538 \mathrm{mg}, 0,706 \mathrm{mg}$, dan 1,213 mg. Hal ini menunjukkan bahwa rokok herbal B dan D memiliki kandungan nikotin yang hampir sama dengan salah satu rokok konvensional yaitu 0,629 mg. Sementara rokok herbal A, C, dan E memiliki kandungan nikotin yang lebih besar dibandingkan dengan rokok konvensional.
\end{abstract}

Kata kunci: Rokok herbal, rokok konvensional, kadar nikotin

\section{PENDAHULUAN}

Perokok aktif sulit meninggalkan kebiasaan merokok karena kandungan nikotin yang memiliki daya adiktif. Rokok dapat memaksa perokok untuk ketagihan. Bila konsumsi rokok dihentikan, perokok bukannya merasa sehat, melainkan akan timbul rasa sakit dan tidak enak yang disebut withdrawal effect atau sakaw (Subagyo, 2011).

Nikotin $\left(\mathrm{C}_{10} \mathrm{H}_{14} \mathrm{~N}_{2}\right)$, merupakan komponen aktif farmakologis yang utama dari tembakau, Nicotiana tabacum, dan juga ditemukan dalam jumlah banyak pada spesies lain dalam famili Solanaceae. Pada konsentrasi rendah nikotin bersifat merangsang (stimulan) yakni nikotin meningkatkan aktivitas, kewaspadaan, dan memori, dan inilah yang 
merupakan salah satu faktor yang berkontribusi pada sifat ketergantungan pada rokok tembakau. Nikotin dapat meningkatkan denyut jantung dan tekanan darah, dan mengurangi nafsu makan. Pada dosis yang tinggi nikotin beraksi sebagai depresan/penekan (Satyajit, 2009).

Rokok berbahan dasar tembakau mengandung nikotin dengan kadar yang cukup tinggi, oleh sebab itu banyak cara dilakukan untuk mengurangi atau meminimalkan kandungan nikotin tersebut. Salah satu inovasi terbaru ialah rokok herbal yang diolah dengan bahan dasar rempah-rempah dengan kadar nikotin yang diklaim sangat kecil atau bahkan tidak ada.

\section{METODE PENELITIAN}

\section{Alat}

Peralatan yang digunakan antara lain spektrofotometer UV-Vis, centrifuge, hotplate, magnetic stirer, labu takar, gelas kimia, corong pisah, micropipet digunakan untuk memindahkan, dan timbangan digital.

\section{Bahan}

Bahan yang digunakan pada penelitian ini antara lain sampel rokok herbal dan rokok konvensional, metanol, aquadest, petroleum eter, $\mathrm{NaOH} 2 \mathrm{M}$, Zink asetat, dan kalium ferrosianida.

\section{Prosedur penelitian}

Ekstraksi rokok dilakukan dengan metanol yang kemudian diaduk selama 30 menit. Selanjutnya ditambah $\mathrm{NaOH} 2 \mathrm{M}$ dan aquadest dan diaduk kembali selama 5-10 menit diatas hotplate dengan suhu $70{ }^{\circ} \mathrm{C}$. Ditambahkan zink asetat dan kalium ferrosianida sebelum disentrifugasi selama 10 menit dengan kecepatan $3000 \mathrm{rpm}$. Supernatan yang diperoleh ditambah petroleum eter dan dipisahkan menggunakan corong pisah dan diambil fraksi petroleum eter.

Penetapan kadar nikotin sampel rokok dilakukan dengan spektrofotometer UV-Vis pada panjang gelombang $262 \mathrm{~nm}$. Hasil absorbansi yang diperoleh selanjutnya dapat dihitung kadarnya dengan menggunakan persamaan linier.

\section{HASIL DAN PEMBAHASAN}

Dari proses pemisahan menggunakan corong pisah, fraksi petroleum eter ditampung dalam vial dan diuapkan pelarutnya sampai habis dan diperoleh nikotin tanpa pelarut. Untuk tahap analisis menggunakan spektrofotometer UV-Vis digunakan metanol sebagai pelarut.

Persamaan regresi linier yang diperoleh dari kurva baku nikotin standar dapat dilihat pada gambar 1. Persamaan ini kemudian digunakan untuk menghitung konsentrasi nikotin dan kadar nikotin perbatang rokok. Menurut penelitian yang dilakukan oleh Peter M. Claiton dkk, absorbansi maksimum nikotin berkisar antara 236-264 nm tergantung kondisi lingkungan asam atau basa. Sehingga dalam penelitian ini digunakan panjang gelombang $262 \mathrm{~nm}$ didapat dari hasil running nikotin standar yang digunakan sebagai pembanding. Hasil perhitungan kadar nikotin perbatang rokok dapat dilihat pada tabel 1 . 


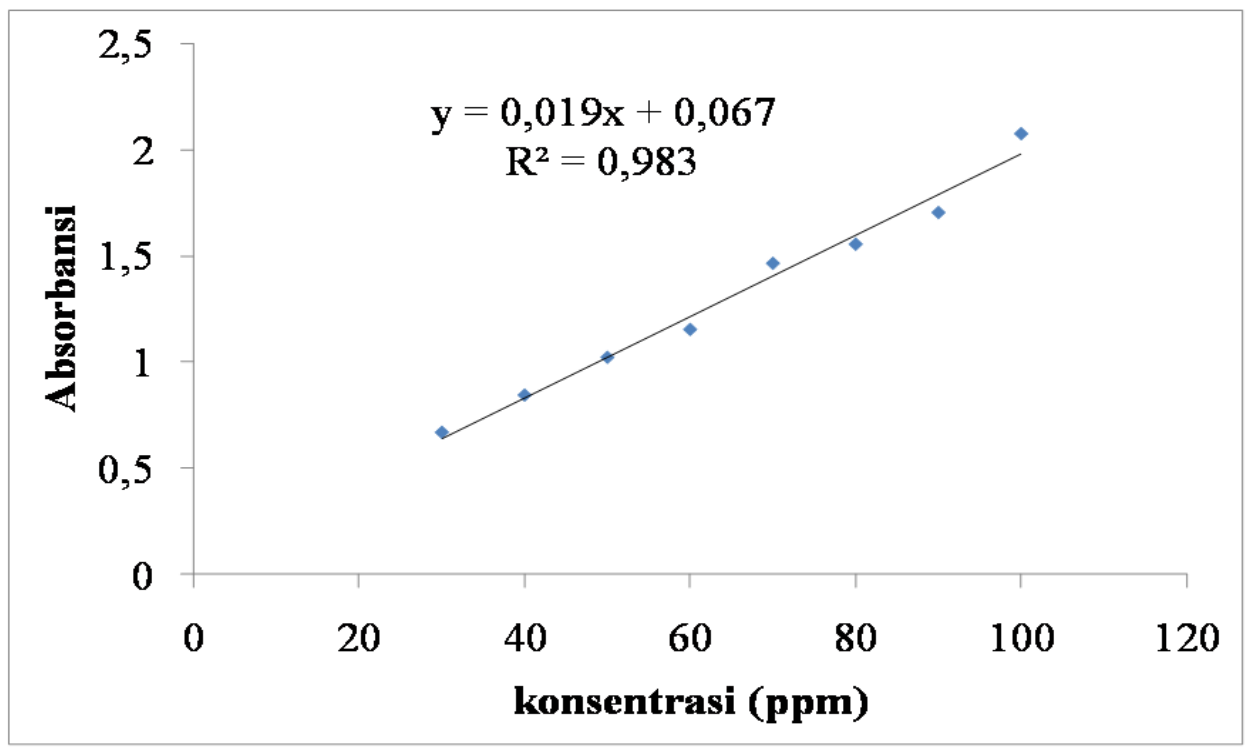

Gambar 1. Serapan standar nikotin

Tabel 1. Hasil analisis kadar nikotin

\begin{tabular}{ccc}
\hline Sampel & Berat $(\mathbf{g})$ & Kadar $(\mathbf{m g})$ \\
\hline M & 0,5813 & 0,629 \\
A & 1,4789 & 1,127 \\
B & 0,7328 & 0,592 \\
C & 2,3163 & 1,538 \\
D & 0,8175 & 0,706 \\
E & 1,5009 & 1,213 \\
\hline
\end{tabular}

Dari data tabel 1 dapat diketahui bahwa berat perbatang rokok tidak mempengaruhi secara linier kadar nikotin yang terkandung dalam setiap kemasan. Hal ini dapat disebabkan oleh simplisia yang digunakan sebagai bahan dasar rokok terdiri dari beberapa campuran herbal dan bentuknya tidak halus sehingga tidak dapat dihomogenkan. Kadar nikotin rokok herbal yang lebih rendah atau mendekati kadar nikotin rokok konvensional hanya sampel B dan D, sedangkan sampel A, C dan E lebih tinggi daripada rokok herbal.

\section{PENUTUP}

Berdasarkan hasil penetapan kadar nikotin diperoleh hasil bahwa rokok herbal B dan D memiliki kandungan nikotin yang hampir sama dengan hasil pengujian kandungan nikotin salah satu rokok konvensional yaitu 0,629 mg. Sementara rokok herbal A, C, dan E memiliki kandungan nikotin yang lebih tinggi dibandingkan rokok konvensional. Padahal kadar nikotin yang tertera pada kemasan rokok herbal sangat rendah bahkan mendekati 0 .

\section{DAFTAR PUSTAKA}

1. Subagyo, Partodiharjo. 2009. Kenali Narkoba dan Musuhi Penyalahgunaannya. Esensi: Jakarta.

2. Peter M. Clayton, dkk. 2013. Spectroscopic Studies On Nicotine and Nornicotine in the UV Region. CHIRALITY 25:288-293. 